\title{
Production of biodiesel from coastal macroalgae (Chara vulgaris) and optimization of process parameters using Box-Behnken design
}

\author{
Shaila Siddiqua* ${ }^{*}$, Abdullah Al Mamun and Sheikh Md. Enayetul Babar
}

*Correspondence:

siddiquashaila@gmail.com

Biotechnology and Genetic Engineering Discipline,

Khulna University, Khulna, Bangladesh

\section{Springer}

\begin{abstract}
Renewable biodiesels are needed as an alternative to petroleum-derived transport fuels, which contribute to global warming and are of limited availability. Algae biomass, are a potential source of renewable energy, and they can be converted into energy such as biofuels. This study introduces an integrated method for the production of biodiesel from Chara vulgaris algae collected from the coastal region of Bangladesh. The Box-Behnken design based on response surface methods (RSM) used as the statistical tool to optimize three variables for predicting the best performing conditions (calorific value and yield) of algae biodiesel. The three parameters for production condition were chloroform $\left(X_{1}\right)$, sodium chloride concentration $\left(X_{2}\right)$ and temperature $\left(X_{3}\right)$. Optimal conditions were estimated by the aid of statistical regression analysis and surface plot chart. The optimal condition of biodiesel production parameter for $12 \mathrm{~g}$ of dry algae biomass was observed to be $198 \mathrm{ml}$ chloroform with $0.75 \%$ sodium chloride at $65^{\circ} \mathrm{C}$ temperature, where the calorific value of biodiesel is $9255.106 \mathrm{kcal} / \mathrm{kg}$ and yield $3.6 \mathrm{ml}$.
\end{abstract}

Keywords: Macroalgae, Chara vulgaris, Algae biodiesel, Transesterification, Oil extraction, Calorific value, Yield

\section{Background}

One of the major priorities of every nation of the world is to provide energy security as energy is must for every sector from transportation to communication, to security and health delivery systems. Natural gas, coal and oil are the primary source of energy production. Consumption of liquid fuels around the world increases consequently from eighty-seven $\mathrm{MMbbl} / \mathrm{d}$ in year 2010 to one hundred and nineteen $\mathrm{MMbbl} / \mathrm{d}$ in year 2040 (US Energy Information Administration 2010). Stressing on the reduction of the energy consumption over the following decades, however, the decrease in demand of liquid fuels seems quite unrealistic.

The idea of alternative fuels generated hundred years ago, when Rudolf Diesel use peanut oil as fuel on diesel engine in 1900 world's fair, Paris (Knothe 2001). This idea falls backwards with the increasing use of liquid fuel and natural gas, but come into focus at the end of twentieth century as the depletion of those sources in near future emerged

(c) 2015 Siddiqua et al. This article is distributed under the terms of the Creative Commons Attribution 4.0 International License (http://creativecommons.org/licenses/by/4.0/), which permits unrestricted use, distribution, and reproduction in any medium, provided you give appropriate credit to the original author(s) and the source, provide a link to the Creative Commons license, and indicate if changes were made. 
alarmingly. In first generation biofuels, food crops are fermented to produce bioethanol, or oils collected from those crops are converted into biodiesel. Wheat or sugar crops are generally used fermentation process, whereas for biodiesel various oil seeds proved as effectual crop. Though, first generation biofuels promises to solve the fuel depletion crisis, it is associated with a number of problems. A debate arises whether it diminishes the carbon dioxide and greenhouse gas emission, because several biofuels releases more carbon to the atmosphere in comparison to their feedstock's confine for growth. On the other hand it creates a serious controversial issue 'fuel versus food', since usage of food crops for fuel production shifted the supply of crops from food market to fuel market. Hence, biofuels are accused for the increasing of food prices (Naik et al. 2009).

To overcome the precincts of first generation biofuels scientists use diverse sources such as organic waste, specific biomass crops, woods, animal waste and food crop waste rather than food crops. These types of biofuels are termed as second generation biofuels and it is less costly than fossil fuels (Ralph et al. 2009). Though the second generation biofuels increase the 'net energy gains', but it still has some problems such as carbon dioxide and greenhouse gas emission which need to solve.

The Third Generation of biofuels is produced focusing all the problems associated with first and second generation biofuels. Rather than using food crops or crop debris it implies algae as a novel source of energy production. First of all it mostly overcomes the issue of carbon dioxide and greenhouse gas emission, as algae uptake them during the growth stage balanced these emissions. Moreover, low cultivation cost and high energy production per acre makes it more enviable source of energy. Land and water which is unsuitable for food crop production can be used to cultivate algae to diminish the use of pure water sources. From diesel to jet fuel, a broad spectrum of fuel can be manufactured from algae (Yonghua and Gilles 2013).

Several researches have been conducted worldwide on algae biodiesel. Biodiesel from microalgae (Chisti 2007); Algae-based biofuels: applications and co-products (Iersel and Flammini 2010); Opportunities and challenges in algae biofuels production (Benemann 2008); A realistic technology and engineering assessment of algae biofuel production (Lundquist et al. 2010); Combustion analysis of algal oil methyl ester in a direct injection compression ignition engine (Hariram and Kumar 2013). Macroalgae use sunlight energy since they are photosynthetic organism, consume more carbon dioxide than the conventional food crops and produce huge amount of biomass per area. Macroalgae could be an immense source of biofuels production as it grows in large amount in fresh water, slightly brackish water to the marine water around the world.

Chara vulgaris is a macroalgae grown in large quantities in the brackish water of coastal region of Bangladesh. This research work is focused on the oil extraction and biodiesel production from Chara vulgaris. Chemical process was applied for oil extraction and transesterification process. Chloroform, methanol, sodium chloride and temperature are significant factors for chemical method of algae biodiesel production. For optimization of chemical method of algae biodiesel production Box-Behnken design was used. The Box-Behnken design (Box and Behnken 1960), which is the response surface methods (RSM), is a very useful statistical tool to optimize multiple variables for predicting the best performing conditions by using a minimum number of experiments (Babar et al. 2007). 


\section{Methods}

Materials

Chara vulgaris was collected from southern part of Khulna, Bangladesh, chosen on the basis of higher accessibility. It is found throughout the year but higher amount found from May to September. Total lipid content of Chara vulgaris is $73.2 \mathrm{mg} / \mathrm{g}$ of dry weight (Dembitsky and Rezanka 1993). Total lipid extraction from algae performed by chemical extraction methods, relying on the chloroform-methanol solvent system, based on the Bligh and Dyer method (Bligh and Dyer 1959). Sodium chloride solution was added to facilitate oil extraction from algae (Axelsson and Gentili 2014). A slight modification of this process was done to facilitate the lipid extraction from Chara vulgaris. Lipid found from this step was then used for the transesterification reaction to produce biodiesel. Chloroform (Loba Chemie, Mumbai, India), Sodium Chloride (Merck, Mumbai, India), Methanol (Merck KGaA, Darmstadt, Germany) and Sodium hydroxide (Merck, Mumbai, India) used for the oil extraction and transesterification process.

\section{Oil extraction}

Debris was separated from Chara vulgaris followed by washing with running water and distilled water. Paste of Chara vulgaris was prepared by using mortar and pestle and then dried in the incubator at $80{ }^{\circ} \mathrm{C}$ for $30 \mathrm{~min} .12 \mathrm{~g}$ of dry algae biomass was mixed with chloroform and methanol, shake vigorously for $10 \mathrm{~min}$. Then $\mathrm{NaCl}$ solution added in the mixture and shake for another $10 \mathrm{~min}$. Resulted mixture was filtered to remove the algal biomass. The clear solution kept for a while to form two distinct phases. The upper phase which contains water and methanol are separated from the lower chloroform-oil phase and discarded. The lower chloroform-oil phase was evaporated to remove excess chloroform and the remaining solution was used for the further treatment.

\section{Biodiesel production}

Alkaline catalyst sodium hydroxide, at an amount of $0.8 \%$ of algal oil was dissolved in the methanol at an amount of $25 \%$ of algal oil by hand shaking and whirling. Resulting sodium methoxide was then added to the preheated (at $50{ }^{\circ} \mathrm{C}$ ) algal oil and air tight the reaction system to avoid the loss of methanol. Temperature was kept constant at $55-65^{\circ} \mathrm{C}$ and heated for $3 \mathrm{~h}$ to complete the reaction. Once the reaction was completed, two major products exist-biodiesel and glycerin. Biodiesel was separated from glycerin by gravity settling as the glycerin was much denser than biodiesel, it settled down at the bottom.

Separated biodiesel contained some soap and methanol. The methanol was removed by vaporization. After the methanol had been removed, the biodiesel was washed with distilled water by liquid-liquid extraction process to remove the soap, and catalyst. The washing procedure was repeated for 3-4 times until the soap totally removed. Remaining water present in the biodiesel was removed by heating it at $100{ }^{\circ} \mathrm{C}$ for $10 \mathrm{~min}$. Finally usable form of biodiesel was found (Mamun et al. 2013).

\section{Properties determination of biodiesel}

The calorific value of algae biodiesel was determined by 'oxygen bomb calorimeter'. Kinematic viscosity and flash point were determined by 'SAYBOLT/REDWOOD viscometer 
bath' and 'flashpoint tester, type-00-ESR' respectively. Density was determined by 'mass/ volume' equation.

\section{Experimental design}

For the optimization of process parameters of algae biodiesel production a very popular statistical tool was applied. Box-Behnken design is an independent quadratic design and requires three levels of each factor (Bligh and Dyer 1959). For three factors, it offers some advantage by entailing a smaller number of runs for three factors. The important factors for the production were chloroform, $\mathrm{NaCl}$ and temperature and the three levels are $+1,0$ and -1 correspondingly. Hence, these factors were considered as the independent variables and their effects on calorific value and yield of algae biodiesel were studied using Box-Behnken design of Response surface methodology (RSM).

The range and levels of experimental variables investigated in this study were presented in Table 1. The central values (zero level) chosen for experimental design were: chloroform- $\mathrm{X}_{1}$ (158.4 $\mathrm{ml}$ i.e. $13.2 \mathrm{ml}$ chloroform/gm of wet algae biomass), $\mathrm{NaCl}-\mathrm{X}_{2}$ $(0.75 \%)$ and temperature- $\mathrm{X}_{3}\left(60^{\circ} \mathrm{C}\right)$. Chloroform level was calculated at the zero level by maintaining the 2:1 ratio of chloroform: methanol.

The second order polynomial equation was used to produce predicted value to facilitate the production of surface plot. The second order polynomial equation uses regression coefficient for the analysis. The second order polynomial equation for three responses:

$$
Y=A_{0}+A_{1} X_{1}+A_{2} X_{2}+A_{3} X_{3}+A_{4} X_{1} X_{2}+A_{5} X_{1} X_{3}+A_{6} X_{2} X_{3}+A_{7} X_{1}^{2}+A_{8} X_{2}^{2}+A_{9} X_{3}^{2}
$$

where $\mathrm{Y}$ is the response; $\mathrm{X}_{1}$ chloroform, $\mathrm{X}_{2} \mathrm{NaCl}$ concentration, $\mathrm{X}_{3}$ temperature; $\mathrm{A}_{0}$ the regression coefficient, $A_{1}-A_{3}$ are the linear coefficients, $A_{4}-A_{6}$ the cross product coefficients, and $A_{7}-A_{9}$ are the quadratic coefficients. The regression analysis, statistical significance and ANOVA were carried out using Microsoft Office Excel. Surface plots and contour plot were developed using the same software along with Sigma Plot software.

\section{Result and discussion}

\section{Production process optimization}

Lipid from Chara vulgaris was extracted by using chloroform, methanol and sodium chloride solvent. Sodium chloride acts as an inhibitory agent between the binding of acidic lipids and denatured lipids during lipid extraction from algae. Crude lipid

Table 1 Coded levels of independent variables in the experimental design

\begin{tabular}{lccc}
\hline Variables* & Coded levels & \\
\cline { 2 - 4 } & $\mathbf{+ 1}$ & $\mathbf{0}$ & $\mathbf{- 1}$ \\
\hline Chloroform $(\mathrm{ml})$ & 118.8 & 158.4 & 198 \\
$\mathrm{NaCl}(\%)$ & 0.70 & 0.75 & 0.80 \\
Temperature $\left({ }^{\circ} \mathrm{C}\right)$ & 55 & 60 & 65 \\
\hline
\end{tabular}

*Where, each of chloroform and $\mathrm{NaCl}$ concentration is given for $12 \mathrm{gm}$ of dry algae biomass 
extract was then transesterified for $3 \mathrm{~h}$ by methanol and sodium hydroxide at $55-65{ }^{\circ} \mathrm{C}$ temperature.

Important physical properties of algae biodiesel produced from Chara vulgaris were determined and it was found that values were resided within the ASTM range of the physical properties of biodiesel presented in Table 2 . The value of viscosity of algae biodiesel was 5.003 centistokes that reside within the American Society for Testing and Materials (ASTM) standard of biodiesel. Higher flash point and calorific value indicate the high quality biodiesel; flash point and calorific value were found $133{ }^{\circ} \mathrm{C}$ and $9255.106 \mathrm{kcal} / \mathrm{kg}$ correspondingly exist within the (ASTM) standard. Density value was also within the (ASTM) standard of biodiesel.

The Box-Behnken design for three independent variables, i.e. chloroform, $\mathrm{NaCl}$ and temperature and the experimental values of calorific value and yield found by using the corresponding design are shown Table 3 . These values were used in the regression analysis where confidence level was kept at $95 \%$ to get the coefficients for each response.

The $p$-values shown in the Table 4 are indicator of the interaction strength between each independent variable and a $p$ value less than 0.05 indicate that the factor interacted significantly with the response. It is observed that all the $p$ values are smaller than 0.05 , indicates that all linear factor, cross product factor and quadratic factor significantly

Table 2 Physical properties of algae biodiesel produced from Chara vulgaris

\begin{tabular}{lll}
\hline Properties & Algae biodiesel & Biodiesel (ASTM) \\
\hline Viscosity & $5.003 \mathrm{Cst}$ & $3.7-5.8 \mathrm{cst}$ \\
Flashpoint & $133^{\circ} \mathrm{C}$ & $>130^{\circ} \mathrm{C}$ \\
Calorific value & $9255.106 \mathrm{kcal} / \mathrm{kg}$ & $8850-10,000 \mathrm{kcal} / \mathrm{kg}$ \\
Density & $0.871 \mathrm{~g} / \mathrm{ml}$ & 0.87 to $0.89 \mathrm{~g} / \mathrm{ml}$ \\
\hline
\end{tabular}

Table 3 The Box-Behnken design matrixes employed for Chara vulgaris biodiesel

\begin{tabular}{|c|c|c|c|c|c|c|}
\hline $\begin{array}{l}\text { Run } \\
\text { no. }\end{array}$ & $\begin{array}{l}\text { Chloroform }\left(X_{1}\right) \\
(\mathrm{ml})\end{array}$ & $\begin{array}{l}\mathrm{NaCl}\left(\mathrm{X}_{2}\right) \\
(\%)\end{array}$ & $\begin{array}{l}\text { Temperature }\left(\mathrm{X}_{3}\right) \\
\left({ }^{\circ} \mathrm{C}\right)\end{array}$ & $\begin{array}{l}\text { Lipid extract } \\
\text { before transes- } \\
\text { terification (ml) }\end{array}$ & $\begin{array}{l}\text { Calorific value (c) } \\
\text { (kcal/kg) }\end{array}$ & $\begin{array}{l}\text { Yield (y) } \\
(\mathrm{ml})\end{array}$ \\
\hline 1 & 118.8 & 0.70 & 60 & 14 & 9167.173 & 3.0 \\
\hline 2 & 198 & 0.70 & 60 & 18 & 9153.926 & 3.4 \\
\hline 3 & 118.8 & 0.80 & 60 & 13 & 9108.31 & 2.9 \\
\hline 4 & 198 & 0.80 & 60 & 19 & 9219.738 & 3.4 \\
\hline 5 & 118.8 & 0.75 & 55 & 15 & 9188.192 & 3.1 \\
\hline 6 & 198 & 0.75 & 55 & 20 & 9242.961 & 3.6 \\
\hline 7 & 118.8 & 0.75 & 65 & 14 & 9132.539 & 3.0 \\
\hline 8 & 198 & 0.75 & 65 & 19 & 9255.106 & 3.5 \\
\hline 9 & 158.4 & 0.70 & 55 & 17 & 9158.281 & 3.2 \\
\hline 10 & 158.4 & 0.80 & 55 & 16 & 9151.03 & 3.1 \\
\hline 11 & 158.4 & 0.70 & 65 & 17 & 9143.935 & 3.2 \\
\hline 12 & 158.4 & 0.80 & 65 & 17 & 9174.205 & 3.2 \\
\hline 13 & 158.4 & 0.75 & 60 & 18 & 9169.471 & 3.3 \\
\hline 14 & 158.4 & 0.75 & 60 & 18 & 9169.471 & 3.3 \\
\hline 15 & 158.4 & 0.75 & 60 & 18 & 9169.471 & 3.3 \\
\hline
\end{tabular}

Where, each of chloroform and $\mathrm{NaCl}$ concentration is given for $12 \mathrm{~g}$ of dry algae biomass 
Table 4 Regression coefficient and corresponding probability values ( $p$-values) for specific responses (calorific value and yield)

\begin{tabular}{|c|c|c|c|c|}
\hline \multirow{2}{*}{$\begin{array}{l}\text { Parameter } \\
\text { (coefficient) }\end{array}$} & \multicolumn{2}{|c|}{ Calorific value (c) } & \multicolumn{2}{|c|}{ Yield value (y) } \\
\hline & Coefficient & $P$-value & Coefficient & $P$-value \\
\hline Constant $\left(\mathrm{A}_{0}\right)$ & 9680.969 & 0.01485 & -19.25 & 0.078605 \\
\hline$X_{1}\left(A_{1}\right)$ & -20.1792 & 0.004058 & -0.00347 & 0.803372 \\
\hline $\mathrm{X}_{2}\left(\mathrm{~A}_{2}\right)$ & 11836.46 & 0.069057 & 66.5 & 0.010884 \\
\hline$X_{3}\left(A_{3}\right)$ & -114.098 & 0.051354 & -0.0775 & 0.620817 \\
\hline$X_{1} X_{2}\left(A_{4}\right)$ & 15.74179 & 0.009388 & 0.012626 & 0.363217 \\
\hline$X_{1} X_{3}\left(A_{5}\right)$ & 0.085604 & 0.076392 & $-2.6 \mathrm{E}-18$ & 1 \\
\hline$X_{2} X_{3}\left(A_{6}\right)$ & 37.521 & 0.272441 & 0.1 & 0.363217 \\
\hline$X_{1} X_{1}\left(A_{7}\right)$ & 0.012962 & 0.050241 & $1.12 \mathrm{E}-19$ & 1 \\
\hline$X_{2} X_{2}\left(A_{8}\right)$ & -11004.2 & 0.017777 & -50 & 0.004867 \\
\hline$X_{3} X_{3}\left(A_{9}\right)$ & 0.59609 & 0.118613 & $2.25 \mathrm{E}-17$ & 1 \\
\hline
\end{tabular}

related to calorific value except one cross product factor and one quadratic factor like temperature. It is seen that chloroform- $\mathrm{NaCl}$ cross product are significantly related to the response (c). Though yield does not show significant relation with chloroform and temperature, but significantly related to the linear factor and quadratic factor like $\mathrm{NaCl}$. $\mathrm{R}^{2}$ value is found by the ANOVA analysis for calorific value and yield are 0.947995 and 0.976573 respectively.

From regression analysis all nine coefficients are used in making the response equation, though not all the factors are significant $(\mathrm{p}<0.05)$. The second-order polynomial equations for calorific value and yield are given below respectively:

$$
\begin{aligned}
Y(c)= & 9680.969-20.1792 X_{1}+11836.46 X_{2}-114.098 X_{3}+15.74179 X_{1} X_{2} \\
& +0.085604 X_{1} X_{3}+37.521 X_{2} X_{3}+0.012962 X_{1}^{2}-11004.2 X_{2}^{2}+0.59609 X_{3}^{2} \\
Y(y)= & -19.25-0.00347 X_{1}+66.5 X_{2}-0.0775 X_{3}+0.012626 X_{1} X_{2} \\
& -(2.6 E-18) X_{1} X_{3}+0.1 X_{2} X_{3}+(1.12 E-19) X_{1}^{2}-50 X_{2}^{2}+(2.25 E-17) X_{3}^{2}
\end{aligned}
$$

where $Y(c)$ is calorific value and $Y(y)$ yield value, $X_{1}, X_{2}$ and $X_{3}$ are coded values for chloroform, $\mathrm{NaCl}$ and temperature correspondingly.

\section{Response surface analysis}

The effect of three variables on the response is seen by holding one factor constant while the other two factors are varied. The values of calorific value and yield are predicted by using Eqs. (2) and (3) and all the 3-D response surface plots are shown in Figs. 1 and 2. Due to three coded levels and the three coded variables total nine combinations are possible for each response. The plots are created with the aim to observe optimum condition from predicted values.

When chloroform is kept constant at $198 \mathrm{ml}$ the surface plot for calorific value showed a higher point at the corner at $0.75 \% \mathrm{NaCl}$ (Fig. 1a). This state produced a good calorific value, both in experiment and prediction. As high calorific value indicates better quality 


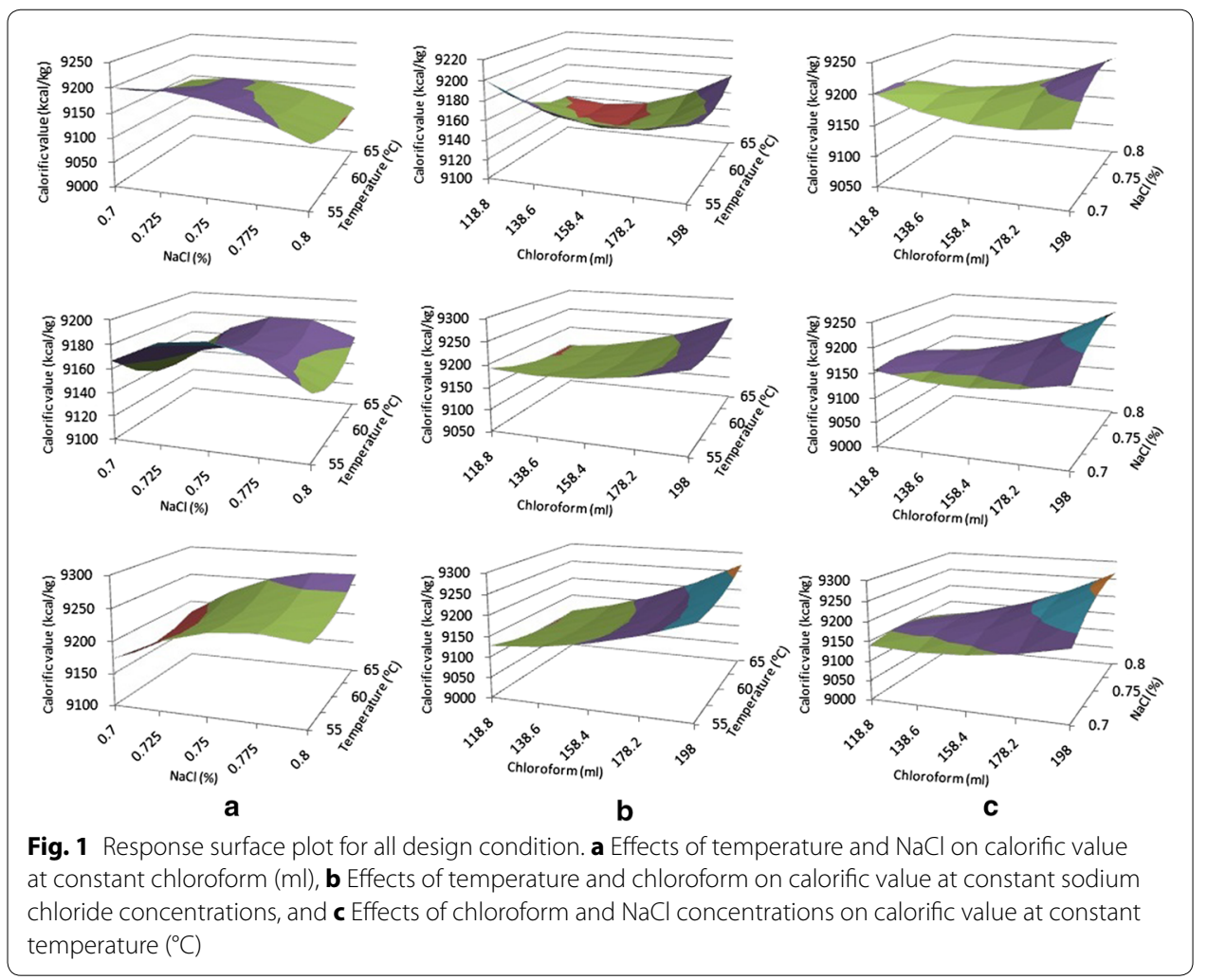

biodiesel, the plot is observed on this basis. However, the calorific value is found much lower for the low level of chloroform. Figure $1 \mathrm{~b}$ can be helpful in understanding the patterns of $\mathrm{NaCl}$ concentration. It can be seen that, high calorific value observed at the middle of $\mathrm{NaCl}$ concentration with increase Chloroform concentration and temperature. From this curve, it can be observed that the pattern of responses varies with respect to chloroform and temperature. When the responses are varied with three factors the relationship became more complex, that is why low value was observed at $0.70 \%$, high value at $0.75 \%$, and low value again at $0.80 \% \mathrm{NaCl}$ concentration (Fig. 1a, b). From this, it can be concluded that at $0.75 \% \mathrm{NaCl}$ concentration calorific value is optimum with varying chloroform concentration and temperature. As shown in the Fig. 1c similar patterns are found for varying temperature factor. All the patterns show low response at low temperature and increases with temperature. Similar results can be seen from Table 3, which contains experimental values. It also found that when temperature is stay constant at $65{ }^{\circ} \mathrm{C}$ (Fig. 1), maximum calorific value $9255.106 \mathrm{kcal} / \mathrm{kg}$ is observed at $198 \mathrm{ml}$ chloroform and $0.75 \% \mathrm{NaCl}$. This condition is considered as optimum and thus used for further study.

Similar 3-D surface plots are created to see the effect of the three variables on the yield response. From Fig. 2a, b it can be perceived that yield increases with increasing chloroform quantity. High response is observed at $198 \mathrm{ml}$ chloroform concentration. Whereas high yield found at the middle point of the $\mathrm{NaCl}$ concentration at $0.75 \%$, low response found in both low level and high level of $\mathrm{NaCl}$ concentration correspondingly at 0.70 and $0.80 \%$. But the effects of different temperature on the response are varied very 


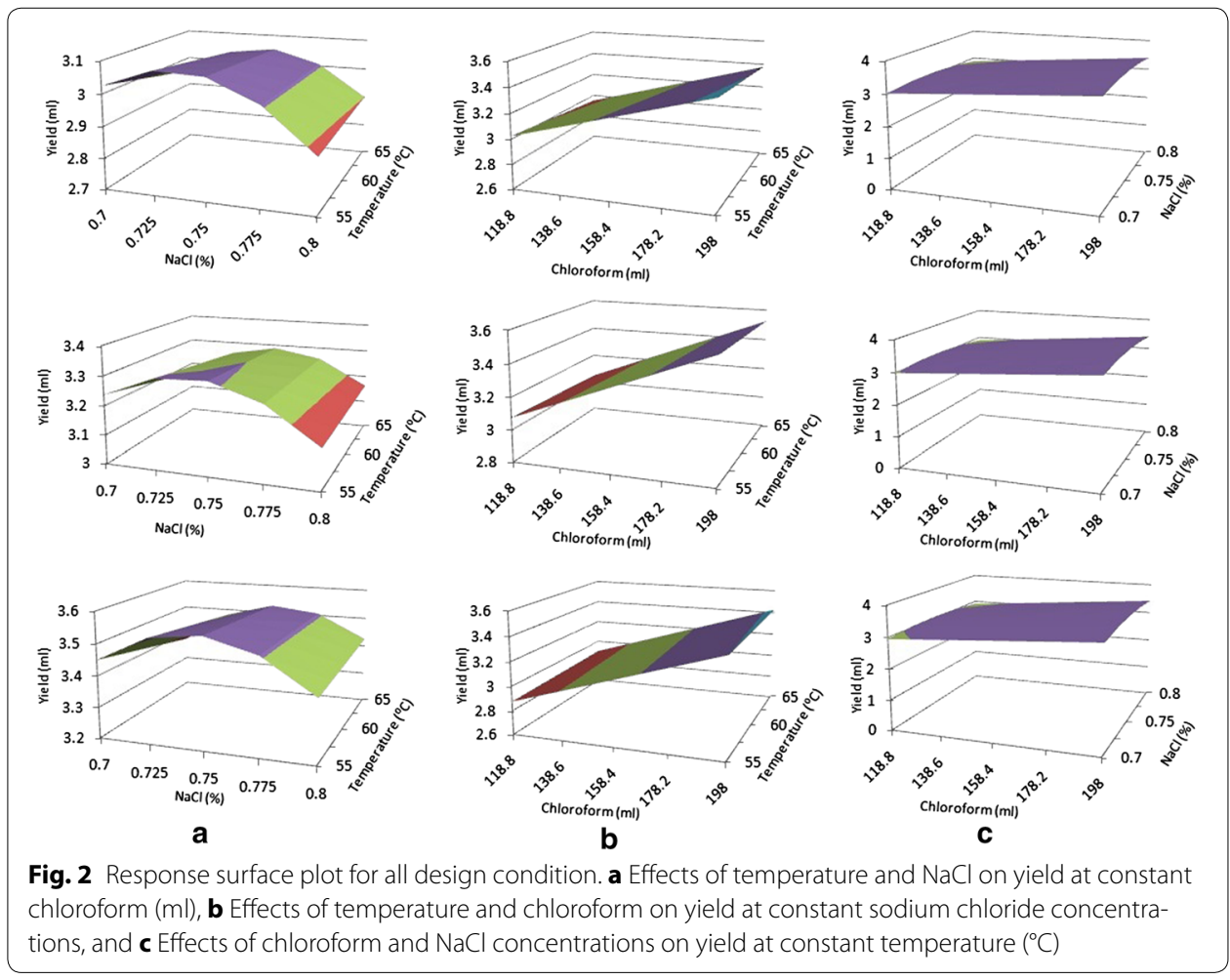

slightly. From this it can be calculated that $\mathrm{NaCl}$ concentration has much more effect on the response rather than chloroform and temperature. Higher response found at $0.75 \%$ $\mathrm{NaCl}$ concentration, $198 \mathrm{ml}$ chloroform and at $65^{\circ} \mathrm{C}$ temperature, which is similar found in experimental value. Thus, this is the optimum condition for yield of algae biodiesel.

\section{Contour plot analysis}

The contour plot is produced by plotting $\mathrm{NaCl}$ concentration ( $\mathrm{Y}$ axis) against chloroform (X axis) for a series of predicted value at a constant temperature of $65{ }^{\circ} \mathrm{C}$. Figures 3, 4 stands for the contour curve for calorific value and yield correspondingly where different values expressed a diverse zone.

Experimentally, only one combination produced maximum calorific value (Table 3 ). From the curve, it is found that several combinations of $\mathrm{NaCl}$ concentrations and chloroform are likely to produce the same line. It can be observed that an extremely smaller portion on the curve in right corner consists of high calorific value $(9260 \mathrm{kcal} / \mathrm{kg})$ zones and smaller lower calorific value $(9120 \mathrm{kcal} / \mathrm{kg})$ zone at the left corner. It is found that a higher calorific value zone could be obtained using a $\mathrm{NaCl}$ concentrations range of $0.76-$ $0.80 \%$ and chloroform range of $196-198 \mathrm{ml}$, while a lower calorific value zone resulted from a $\mathrm{NaCl}$ concentrations range of $0.78-0.80 \%$ and chloroform range of $120-130 \mathrm{ml}$. This curve signifies that high calorific value is more responsive to $\mathrm{NaCl}$ concentrations than to chloroform when temperature is kept constant.

Figure 4 demonstrates that a very smaller portion on the curve in right edge consists of high yield $(3.5 \mathrm{ml})$ zones and smaller lower yield $(3.0 \mathrm{ml})$ zone at the lower left corner. It is found that a higher calorific value zone could be obtained using a $\mathrm{NaCl}$ concentrations 


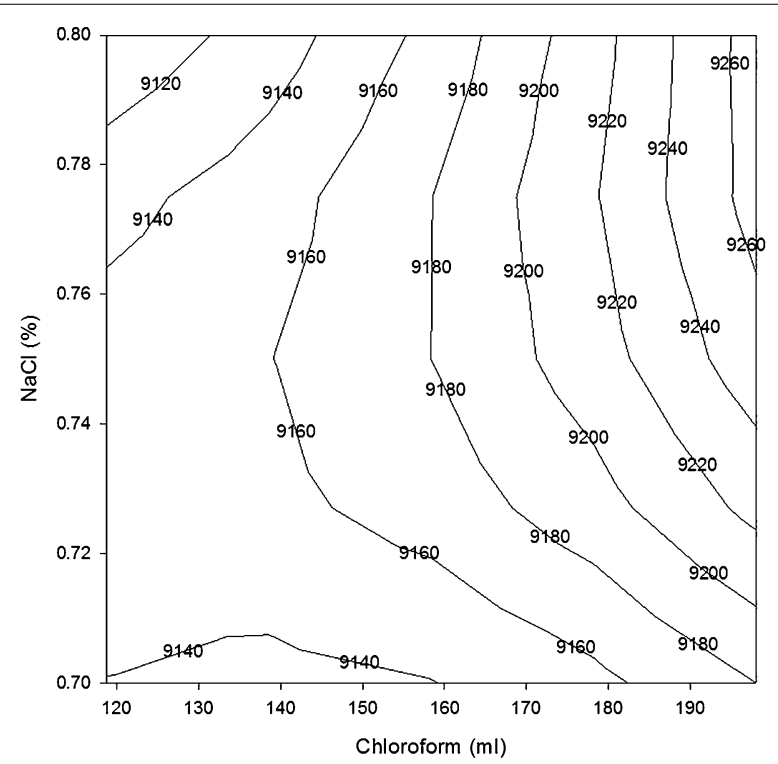

Fig. 3 Contour plot showing calorific value at various $\mathrm{NaCl}$ concentrations and chloroform at constant $65^{\circ} \mathrm{C}$ temperature

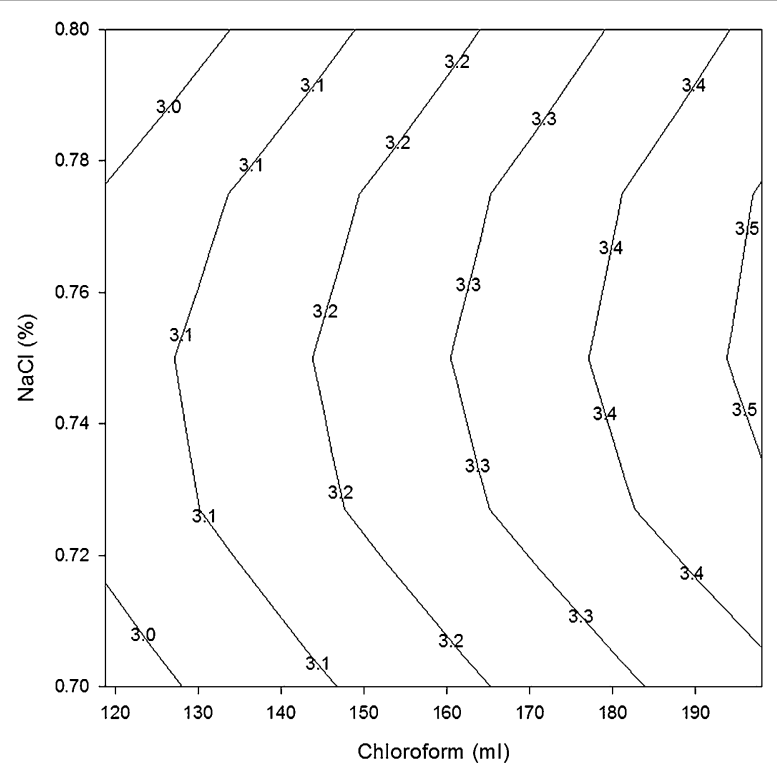

Fig. 4 Contour plot showing yield at various $\mathrm{NaCl}$ concentrations and chloroform at constant $65^{\circ} \mathrm{C}$ temperature

range of $0.73-0.77 \%$ and chloroform range of $196-198 \mathrm{ml}$. While a lower calorific value zone resulted from a $\mathrm{NaCl}$ concentrations range of $0.70-0.71 \%$ and chloroform range of $120-128 \mathrm{ml}$. This curve point out that high calorific value is more responsive to $\mathrm{NaCl}$ concentrations than to chloroform when temperature is kept constant.

The process is validated by random selection of few values from the design combination. Experimental and predicted values of calorific value and yield are shown in the 
Table 5 Experimental and predicted calorific values for method validation experiment

\begin{tabular}{|c|c|c|c|c|c|c|}
\hline \multirow[t]{2}{*}{ Chloroform (ml) } & \multirow[t]{2}{*}{$\mathrm{NaCl}(\%)$} & \multirow[t]{2}{*}{ Temperature $\left({ }^{\circ} \mathrm{C}\right)$} & \multicolumn{2}{|c|}{ Calorific value (kcal/kg) } & \multicolumn{2}{|l|}{ Yield (ml) } \\
\hline & & & Experimental & Predicted & Experimental & Predicted \\
\hline 118.8 & 0.7 & 55 & 9116.294 & 9147.441 & 3.1 & 3.0649 \\
\hline 118.8 & 0.8 & 65 & 9123.083 & 9114.326 & 3 & 2.9529 \\
\hline 158.4 & 0.75 & 65 & 9157.839 & 9176.299 & 3.2 & 3.2610 \\
\hline 198 & 0.8 & 65 & 9204.372 & 9222.489 & 3.4 & 3.4201 \\
\hline
\end{tabular}

Table 5 reveal that they are quite close. This research validated that chloroform; $\mathrm{NaCl}$ concentration and temperature are critical factor for algal biodiesel production.

\section{Conclusion}

Biodiesel was produced from macroalgae Chara vulgaris and the three production parameters were optimized using Box-Behnken design to predict the best performing conditions for calorific value and yield of algae biodiesel. The three parameters for production condition were chloroform, sodium chloride concentration and temperature. Optimal conditions were estimated by the aid of statistical regression analysis and surface plot chart. The Optimal condition of biodiesel production parameter was recognized to be $198 \mathrm{ml}$ Chloroform with $0.75 \%$ sodium chloride at $65^{\circ} \mathrm{C}$ temperature where the calorific value of biodiesel was $9255.106 \mathrm{kcal} / \mathrm{kg}$ and yield $3.6 \mathrm{ml}$. This study signifies that the biodiesel produce from Chara vulgaris could be used as a possible alternative fuel and further study will make it suitable for large scale production.

Authors' contributions

All authors contribute in all stages of research. All authors read and approved the final manuscript.

\section{Acknowledgements}

The authors acknowledge Khulna University, Bangladesh for the financial and technical support and Department of Chemical Engineering of Bangladesh University of Engineering and Technology for chemical analyses.

\section{Competing interests}

The authors declare that they have no competing interests.

Received: 1 June 2015 Accepted: 9 November 2015

Published online: 24 November 2015

References

Axelsson M, Gentili F (2014) A single-step method for rapid extraction of total lipids from green microalgae. PLoS One. doi:10.1371/journal

Babar SME, Song SJ, Hasan MN (2007) Yoo Y S (2007) Experimental design optimization of the capillary electrophoresis separation of leucine enkephalin and its immune complex. Wiley Inter Science J Sep Sci 30:2311-2319. doi:10.1002/ jssc.200700145

Benemann JR (2008) Opportunities and challenges in algae biofuels production. http://www.fao.org/uploads/media/ algae_positionpaper.pdf. Accessed 17 Mar 2015

Bligh EG, Dyer WJ (1959) A rapid method of total lipid extraction and purification. Can J Biochem Physiol 37(8):911-917

Box GEP, Behnken DW (1960) Technometrics 2:455-475

Chisti Y (2007) Biodiesel from Microalgae. Biotechnol Adv 25(2007):294-306

Dembitsky VM, Rezanka T, Rozentsvet OA (1993) Lipid composition of three macrophytes from the Caspian Sea. Phytochemistry 33(5):1014-1019

Hariram V, Kumar GM (2013) Combustion analysis of algal oil methyl ester in a direct injection compression ignition engine. J Eng Sci Technol 8(1):77-92

lersel SV, Flammini Al (2010) Algae-based biofuels: applications and co-products. In: FAO Environmental and Natural Resources Service Series, No. 44-FAO, Rome 2010. ISBN 978-92-5-106623-2

Knothe G (2001) Historical perspectives on vegetable oil-based diesel fuels. Inform 12:1103-1107 
Lundquist TJ, Woertz IC, Quinn NWT, Benemann JR (2010) A realistic technology and engineering assessment of algae biofuel production. J Eng Sci Technol 8(1):77-92

Mamun AA, Siddiqua S, Babar SME (2013) Selection of an efficient method of biodiesel production from vegetable oil based on fuel properties. Int J Eng Trends Technol V4(8):3289-3293

Naik SN, Vaibhav VG, Prasant KR, Ajay KD (2009) Production of first and second generation biofuels: a comprehensive review. Renew Sustain Energy Rev 14(2010):578-597. doi:10.1016/j.rser.2009.10.003

Ralph EHS, Warren M, Jack NS, Michael T (2009) An overview of second generation biofuel technologies. Bioresour Technol 101(2010):1570-1580. doi:10.1016/j.biortech.2009.11.046

US Energy Information Administration (2010) International energy outlook 2010: world energy demand and economic outlook. http://www.eia.doe.gov/oiaf/ieo/world.html. Accessed 15 Mar 2015

Yonghua LB, Gilles P (2013) Third-generation biofuels: current and future research on microalgal lipid biotechnology. EDP Sciences 20(6):D606. doi:10.1051/ocl/2013031

\section{Submit your manuscript to a SpringerOpen ${ }^{\circ}$} journal and benefit from:

- Convenient online submission

- Rigorous peer review

- Immediate publication on acceptance

- Open access: articles freely available online

- High visibility within the field

- Retaining the copyright to your article 